\title{
Competency based training in Irish
}

\section{psychiatry}

\author{
Izu Nwachukwu
}

Ir J Psych Med 2009; 26(2): 50-53

The goal of undertaking postgraduate training in psychiatry is to become a competent specialist, and the educational model under which one is trained and assessed is crucial in achieving this goal. Over the years, traditional training models have emphasised what trainees know, over a given period of time, with outcomes assessed mainly by simple recall of knowledge. ${ }^{1}$ While these traditional approaches have met with varying levels of success, they are less than optimal when the goal is to train individuals to perform specific, job-related skills. ${ }^{2}$ This recognition has led to a global move towards competency based training models ${ }^{3-5}$ where the focus of training and assessment is the mastery of specific knowledge and skills as well as the conduct of the doctor in day-to-day clinical situations. In this article, a general overview of competency-based training in psychiatry is followed by a review of recent developments in Ireland in a global context.

\section{The concept of competency based training}

One definition of competency is a combination of related knowledge, skills and attitudes that are necessary for the performance of a major task or function in the work setting. Competence must be demonstrable. It correlates with performance; can be measured against well-accepted standards; and can be improved via training and development. ${ }^{6}$ Competency based training seeks to ensure that trainees completing their programme have achieved learning outcomes that correlate with the ability to provide competent care. The focus is on performance rather than simple recall of knowledge. All core domains of knowledge, skills and attitudes as well as other aspects of the doctor-patient relationship that underpin professionalism are taught and assessed. Under this model, the trainee remains in training until they have been shown to have the required knowledge and skills and can apply them independently. ${ }^{7}$ Compared with traditional approaches, competency-based training potentially leads to an individualised flexible training, transparent standards, and increased public accountability. ${ }^{4}$

\footnotetext{
*Izu Nwachukwu, MB.BS, MRCPsych, Senior Registrar, St Vincent's University Hospital, Dublin 4, Special Lecturer, UCD Department of Psychiatry \& Mental Health Research, Dublin. Chair, Trainees' Committee, College of Psychiatry of Ireland. Chair, Competence-Based Training Working Group, European Federation of Psychiatric Trainees (EFPT). Member of Core Working Group on Competence-Based Training, European Board of Psychiatry. Email: izunwachukwu@hotmail.com.

${ }^{\star}$ Correspondence

SUBMITTED: MAY 21, 2008. ACCEPTED: MARCH 5, 2009.
}

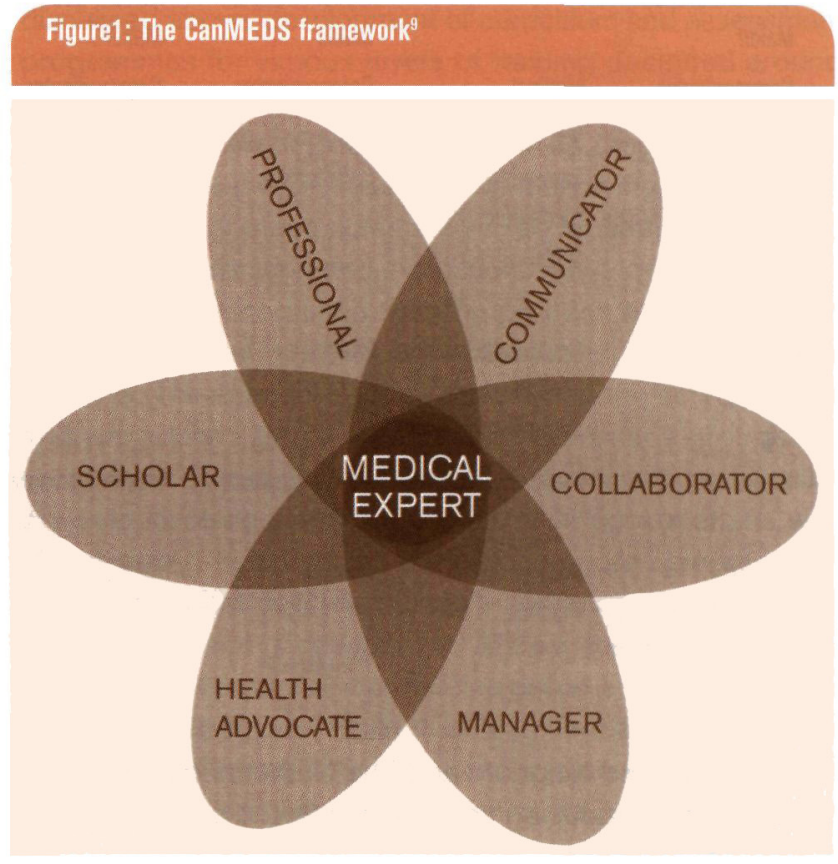

\section{Evolution of competency based training}

Competency-based training as presently conceptualised can be traced back to the vocational training movement of the 1980s. Building training around defined competencies aided the development of measurable outcomes based on performance, and made quality assurance easier. This move towards outcomes in medical education was inspired by the work of Prof Ralph Tyler of the University of Chicago who, in 1949, stressed that the success of educational activities should be judged by how well students achieved measurable outcomes. ${ }^{8}$ Medical core competencies thus, grew out of this 'outcomes movement' and was pioneered by the Royal College of Physicians and Surgeons of Canada with the CanMEDS Framework ${ }^{9}$ in the 1990s (see Figure 1).

It was also within this context, in 1997, that the Accreditation Council for Graduate Medical Education (ACGME) in the US made a commitment to learning outcomes as an educational tool. Their 'outcome project' led to the identification of six core competencies that formed the basis of competency based training curricula for all medical specialities in the United States. ${ }^{10}$ Of note, both the Canadian and American frameworks were products of extensive and iterative consultation processes that involved all stakeholders in mental healthcare provision in those countries.

Building on these developments in Canada and the United States, competency based training has recently been introduced into postgraduate training on a nationwide scale in other countries. ${ }^{5}$ Australia and New Zealand have defined medical core competencies and have designed their curricula based on them. Also, European countries like Sweden, 
Table 1: Gommen core competencies in selected countries

\begin{tabular}{|c|c|c|c|c|c|c|c|}
\hline Canada & United States & $\begin{array}{l}\text { Australial } \\
\text { New Zealand }\end{array}$ & EU & United Kingdom & Denmark & Sweden & Netherlands \\
\hline $\begin{array}{l}\text { (RCPSC } \\
\text { CanMEDS) }\end{array}$ & (ACGME/ABMS) & $\begin{array}{l}\text { (RANZCP Goals of } \\
\text { Training) }\end{array}$ & $\begin{array}{l}\text { (UEMS - Profile } \\
\text { of a psychiatrist) }\end{array}$ & $\begin{array}{l}\text { (GMC - Good } \\
\text { Medical Practice) }\end{array}$ & $\begin{array}{l}\text { (CanMEDS } \\
\text { revised) }\end{array}$ & & $\begin{array}{l}\text { (Dutch Central } \\
\text { College of Medical } \\
\text { Specialities) }\end{array}$ \\
\hline $\begin{array}{l}\text { Medical Expert/ } \\
\text { Clinical Decision } \\
\text { Maker }\end{array}$ & Patient Care & $\begin{array}{l}\text { Medical Expert/ } \\
\text { Clinical Decision } \\
\text { Maker }\end{array}$ & $\begin{array}{l}\text { Medical Expert/ } \\
\text { Clinical Decision } \\
\text { Maker }\end{array}$ & Good Clinical Care & Medical expert & $\begin{array}{l}\text { Medical } \\
\text { Competence }\end{array}$ & $\begin{array}{l}\text { Medical } \\
\text { Performance }\end{array}$ \\
\hline Communicator & $\begin{array}{l}\text { Medical } \\
\text { Knowledge }\end{array}$ & Communicator & Communicator & $\begin{array}{l}\text { Maintaining Good } \\
\text { Clinical Practice }\end{array}$ & Communicator & Communication & Communication \\
\hline Collaborator & $\begin{array}{l}\text { Interpersonal and } \\
\text { Communication } \\
\text { Skills }\end{array}$ & Collaborator & Collaborator & $\begin{array}{l}\text { Teaching } \\
\text { and training, } \\
\text { appraising and } \\
\text { assessing }\end{array}$ & Collaborator & Leadership & Collaboration \\
\hline Manager & $\begin{array}{l}\text { Practice-based } \\
\text { Learning an } \\
\text { Improvement }\end{array}$ & Manager & Manager & $\begin{array}{l}\text { Relationships with } \\
\text { Patients }\end{array}$ & $\begin{array}{l}\text { Manager and } \\
\text { administrator }\end{array}$ & $\begin{array}{l}\text { Medical Science } \\
\text { and Quality } \\
\text { Enhancement }\end{array}$ & $\begin{array}{l}\text { Knowledge \& } \\
\text { Science }\end{array}$ \\
\hline Health Advocate & Professionalism & Health Advocate & Health Advocate & $\begin{array}{l}\text { Working with } \\
\text { Colleagues }\end{array}$ & Health promoter & & $\begin{array}{l}\text { Community } \\
\text { Performance }\end{array}$ \\
\hline Scholar & $\begin{array}{l}\text { Systems-Based } \\
\text { Practice }\end{array}$ & Scholar & Scholar & Probity & Academic & & Management \\
\hline Professional & & Professional & Professional & Health & Professional & & Professionalism \\
\hline
\end{tabular}

Denmark, United Kingdom and The Netherlands are all well underway to introducing competency-based curricula in their postgraduate medical training ${ }^{5,11}$ based on defined core competencies (see Table 1).

\section{Drivers for change}

The focus on outcomes in medical education grew out of society's increasing demands for accountability in professional training standards. A rapidly evolving body of medical knowledge and growing awareness and expectations of patients and society has fast eroded the once omnipotent view of physicians. Third party healthcare providers, governments and advocacy groups now demand transparency in the process of certification, re-certification and maintenance of certification of doctors. Besides, when doctors are found negligent, it has not only been on the basis of lack of clinical knowledge but also on the basis of deficiencies in those other generic (softer) skills and attitudes that underpin our professionalism. The medical profession has therefore moved to monitor itself, as the establishment of external agencies to do so might otherwise be inevitable.

The advent of competency-based training in medical education is not aimed at radically changing the training of doctors. The difference is that while traditional medical education articulated competence around core medical expertise, the CanMEDS framework and all other similar frameworks also emphasise those aspects of traditional medical education that have not been previously explicit, therefore promoting the development and assessment of these broader competencies. Thus, in these frameworks, medical expertise becomes the central role around which these other softer competencies are developed, preserving the holistic view of the role of a doctor (see Figure 1).

\section{Impact on European psychiatry}

Increasing mobility of labour across an expanding common European market has driven a need for a common sense of European professional identity. Harmonisation and mutual recognition of training programmes across Europe has therefore become inevitable. It is in this context that the Union of European Medical Specialists (UEMS) Board of Psychiatry, responsible for stipulating minimum training requirements in psychiatry in Europe, set up a permanent working group on competency-based training. This group is tasked with developing a competency based curriculum framework as a benchmark model for training across Europe. They have produced 'The Profile of a Psychiatrist'12 which sets out seven core competencies that define a specialist in Psychiatry from a European perspective (see Table 1). Their work has been adapted largely from the CanMEDS framework, and is similar to the models adopted by Australia, New Zealand and the United States. Irish psychiatry is represented in this group through their representative at the European Federation of Psychiatric Trainees (EFPT). Table 1 illustrates some of the international frameworks derived to date.

\section{The Irish perspective \\ Background}

Until recently, the Irish Psychiatric Training Committee (IPTC) was the statutory body regulating psychiatric training in Ireland. Alongside the IPTC, the Royal College of Psychiatrists (through its Irish division) provided accreditation and educational approval to training schemes and programmes. The educational programme has been based on traditional methods that are focused on syllabic contents and the time spent in the programme. There are currently 12 training schemes with approximately 500 trainees in Ireland. Training 
comprises three to four years of basic training as $\mathrm{SHO}$ / registrar, followed by another three to four years of higher training as senior registrar leading to the award of Certificate of Satisfactory Completion of Training (CSCT) and entry onto the specialist register of the Irish Medical Council.

In recent years, several reports and assessments of the state of medical education in Ireland have been published. In 2006, the Fottrell report ${ }^{13}$ called for urgent and structured reforms in undergraduate medical education in Ireland. It recommended outcome-based curricula built on identified core competencies, as well as a programme structure that outlines how these outcomes are to be achieved and assessed. It also called for in-built quality assurance mechanisms in the educational programmes of all medical schools.

Focusing on postgraduate medical education, the Buttimer report ${ }^{14}$ also published in 2006 advised the facilitation of trainees to address skills deficits that hinder entry onto the specialist register. One of their key recommendations was the development of a governance structure to drive reform in medical education with an emphasis on effectiveness and efficiency. ${ }^{14}$

Another landmark report on the future of Irish psychiatry ( $A$ Vision for Change) recommended reform and increased investments in medical education and research. ${ }^{15}$ The new Medical Practitioners' Act 2007 also emphasises the development and maintenance of professional competence and the promotion of lifelong learning across all medical specialties.

The Irish society has experienced unprecedented changes in socio-cultural and demographic dynamics in the last decade. The current economic downturn has put even more pressures on finite healthcare resources. Psychiatric trainees in Ireland must therefore be competent to deliver an effective service to this diverse population, within the budgetary constraints that apply.

\section{On-going changes in postgraduate training structure}

On January 1, 2009, a new College of Psychiatry with statutory responsibility to regulate training in Ireland came into being. The emergence of this new college has set postgraduate psychiatric training in Ireland on a new direction, providing an opportunity for needed reforms to be implemented. In recognition of recent advances in medical education, ongoing developments in European psychiatry and local policy initiatives and recommendations, Irish psychiatry has embraced the concept of competency-based training. Different steering groups are currently and separately developing curriculum and assessment frameworks for basic specialist training (BST).

The curriculum for the first year of BST has been completed and is designed around clinical and non-clinical competencies with defined educational outcomes. The curriculum for the rest of the basic training years is now being developed, and will follow the same model. Plans are also underway to develop a curriculum for the National Higher Specialist Training (HST) Scheme. The steering group on assessments is currently developing a robust system, expected to assess what trainees know (knowledge); can do (competence); and actually do in the work setting (performance). Under this project, a set of workplace-based assessments is currently being piloted, and an indigenous membership examination that is expected to be in place in the next few years is being developed. Furthermore, one of the three 'pillars' of the college has been dedicated to promoting Continued Professional Development (CPD) and is currently defining core competencies for the various sub-specialities in psychiatry, upon which a programme of lifelong learning and performance evaluation will be built.

\section{Irish developments in a global context}

It is a welcome development that Irish psychiatry is embracing the concept of competency-based training. As discussed above, development of curriculum and assessment programmes for various levels of training designed around educational outcomes is well advanced. However, some have argued that a competency based training programme is only as effective as the process used in identifying the essential job skills and competencies as well as for setting guidelines for its implementation and evaluation. ${ }^{2}$

It is widely recognised that the process of defining core competencies should involve consultation and consensus building with specialties, profession leaders, service users and providers as well as carer and advocacy groups. As described above, the CanMEDS framework and similar projects involved extensive and iterative consultations with stakeholders. It is on the basis of these core competencies that curricula are designed, along a continuum of certification and maintenance of certification. To date, there have been no studies on what core competencies define a psychiatrist from an Irish perspective. While it is likely that any findings will not be very different from what obtains elsewhere, seeking a consensus with stakeholders in Irish psychiatry may be a step in the right direction.

One other result of the increasing demand for accountability in medical education is that every training programme must document whether trainees are achieving the objectives mandated by agreed standards. This requires developing dependable methods of assessing performance within these set competencies. The idea that assessment drives learning is now well recognised, and has led to assessment systems becoming integral parts of the curriculum. ${ }^{16}$

Developing curriculum and assessment systems separately as appears to be occurring in Ireland must therefore be re-examined. On the other hand, given that developing valid and reliable competency based assessment tools de novo can be a monumental task, the approach to adopt and pilot tools developed elsewhere seems very reasonable. Besides the issue of curriculum design, trainees in the UK and Netherlands have highlighted the need for adequate information to be made available to trainers, trainees and other stakeholders about the implementation of competency-based training, its assessment and potential benefits. ${ }^{17}$ This should therefore be addressed in the Irish project. The role of a regulator and a process for reviewing the curriculum and assessments in the future should also be considered as part of the programme development.

Competency based training is not without potential limitations. If applied inappropriately, it can lead to demotivation and a focus on minimum acceptable standards. ${ }^{4}$ It has huge resource implications, which in the current economic downturn is significant. Training the trainers and providing them with administrative support and protected time for training would be expensive, yet indispensable. Considerable consultants' 
and trainees' time would also be spent away from direct patient care during assessment and feedback sessions. ${ }^{17}$ Adequate organisational and infrastructural support must be secured and funds ring-fenced to support training and research. Careful planning will also be needed to relieve the present tension between pressures of service provision and the delivery of the highest standards of training.

The creation of academic consultant posts for teaching may be needed in all approved training centres or schemes. Creating a faculty of academic psychiatry in the College should also be considered. This special interest group would be made up of psychiatrists with expertise, experience and interest in medical education. The overall aim would be to promote the ethos of evidence based medical education in Irish psychiatry. They would take a longitudinal view of education in psychiatry in Ireland across undergraduate, postgraduate and continued professional development levels. They would facilitate collaboration between the various groups involved in describing and assessing competencies across all levels of training and expertise, and advise the College council on medical education matters.

\section{Conclusion}

It is now widely recognised that competency based training is a more effective method of medical education, compared to traditional methods. That Irish psychiatry has embraced it as the cornerstone of its postgraduate psychiatry training and continued professional development is a welcome development.

Great care and attention to detail must be ensured at the design, delivery and evaluation stages to ensure maximum effectiveness and overcome its potential limitations. There will be cost in terms of time and other resources but hopefully, these will compare favourably with the benefits that competency based training and assessments bring to the learning experience.

\section{Acknowledgements}

I am grateful to Drs Caroline Maher, Allys Guerandel and Professor Kevin Malone for their invaluable advice in the writing of this article. I am also immensely grateful to Professor Michael Gill for his inspiration in initiating this project, and for his guidance in the earlier drafts.

Declaration of Interest: None.

\section{References}

1. Dinesh Bhugra. A new era in Psychiatric training and assessment. Adv Psychiatric Train 2007; 13: 237-238.

2. Sullivan RL. US Agency for international development. The Competency-Based Approach to Training. www.reproline.jhu.edu/english/6read/6training/cbt/cbt.htm

3. Dinesh Bhugra. The new curriculum for psychiatric training. Adv Psychiatric Train 2006; 12: 393-396.

4. Wai-Ching Leung. Competency based medical training: review. BMJ 2002; 325 .

5. Ten Cate et al. Competency-Based Postgraduate Training: Can We Bridge the Gap between Theory and Clinical Practice? Acad Med 2007; 82(6): 542-547.

6. Scott P Barry. The quest for competencies. Training Magazine 1996; July.

7. Donlin M Long Competency-based Residency Training: The Next Advance in Graduate Medical Education. Acad Med 2000; 75(12).

8. Tyler R. Basic Principles of Curriculum and Instruction. Chicago: University of Chicago, 1949.

9. The Royal College of Physicians and Surgeons of Canada. Canadian Medica Education Directions for Specialists 2000 Project. www.easom.org/Data/ documentation/CanMEDS_e.pdf. 1996; Sept.

10. Accreditation Council for Graduate Medical Education (ACGME) Outcome Project: ACGME General Competencies Version 1.3. Chicago, ACGME, 2000

11. Post Graduate Medical Education Training Board. 2004a and 2004b, London, UK. 12. UEMS. 2005. The Profile of a Psychiatrist. www.uemspsychiatry.org/section/ reports/2005Oct-PsychiatristProfile.pdf

13. The Fotrell Report. Department of Health \& Children, Dublin, 2006; www.dohc.ie/ publications/fottrell.html?lang=en

14. The Buttimer Report. Department of Health \& Children, Dublin, 2006. www.dohc. ie/publications/buttimer.html

15. Department of Health \& Children, Dublin, 2006. A Vision for Change. www.dohc.ie/ publications/vision_for_change.html

16. Harden RM. Developments in outcome-based education. Med Teacher 2002; 24 117-120.

17. Oakley C, Malik A, Kamphuis F. Introducing competency-based training in Europe: an Anglo-Dutch perspective. Int Psychiatry J 2008; 5(4). www.rcpsych.ac.uk/pdf/ IPv5n4.pdf 


\section{Seroquel $\times R^{P}$}

Acute Mania

and

Major

Depressive

Episodes

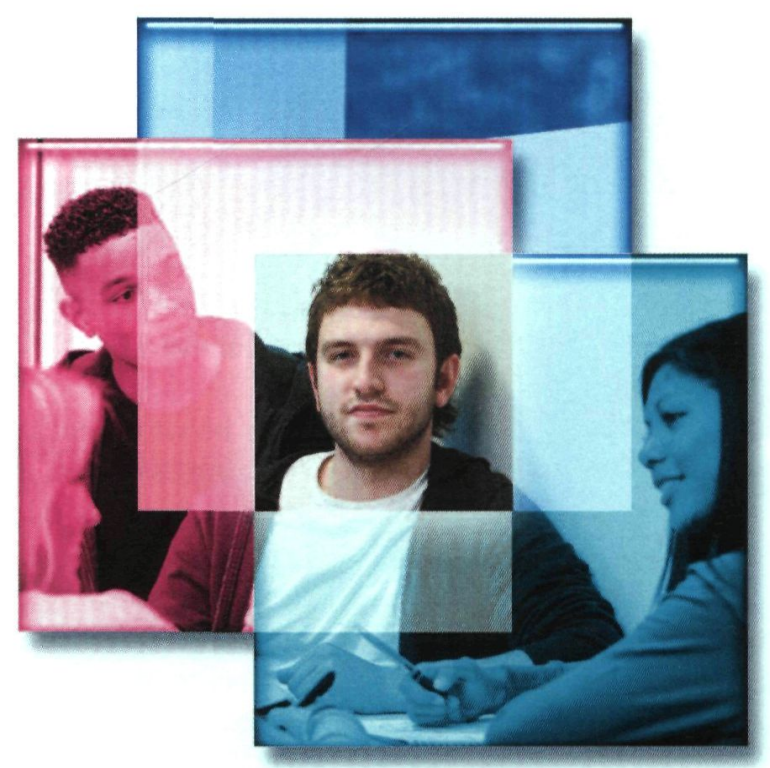

\section{in Bipolar Disorder}

\section{BSeroquel XR}

Rapid symptom improvement as early as:

- DAY 4 in Bipolar Mania

- DAY 7 in Bipolar Depression 
Helping your patients make their life feel normal again.

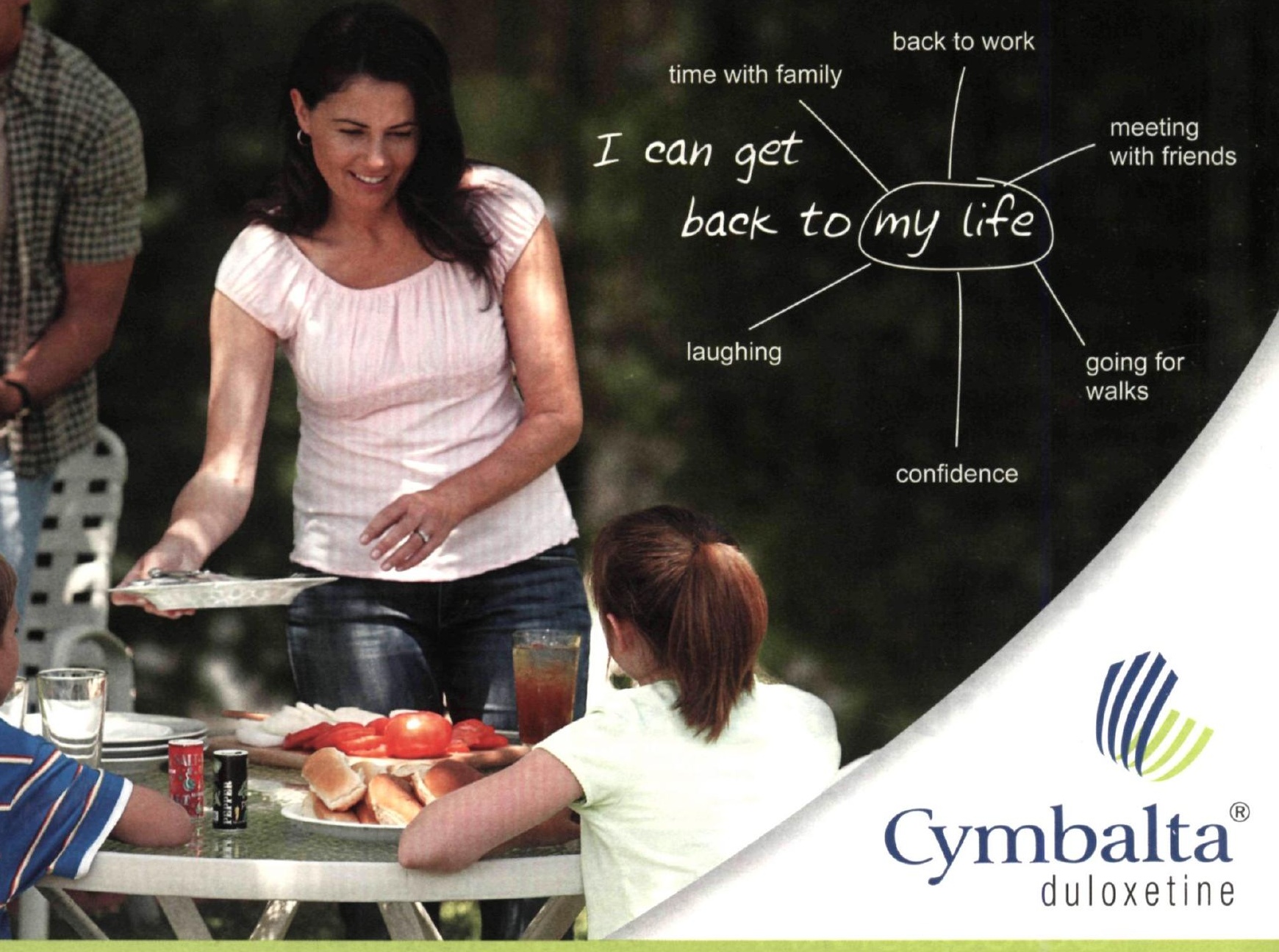

In determining remission from depression, patients consider a return to one's usual, normal self as very important.'

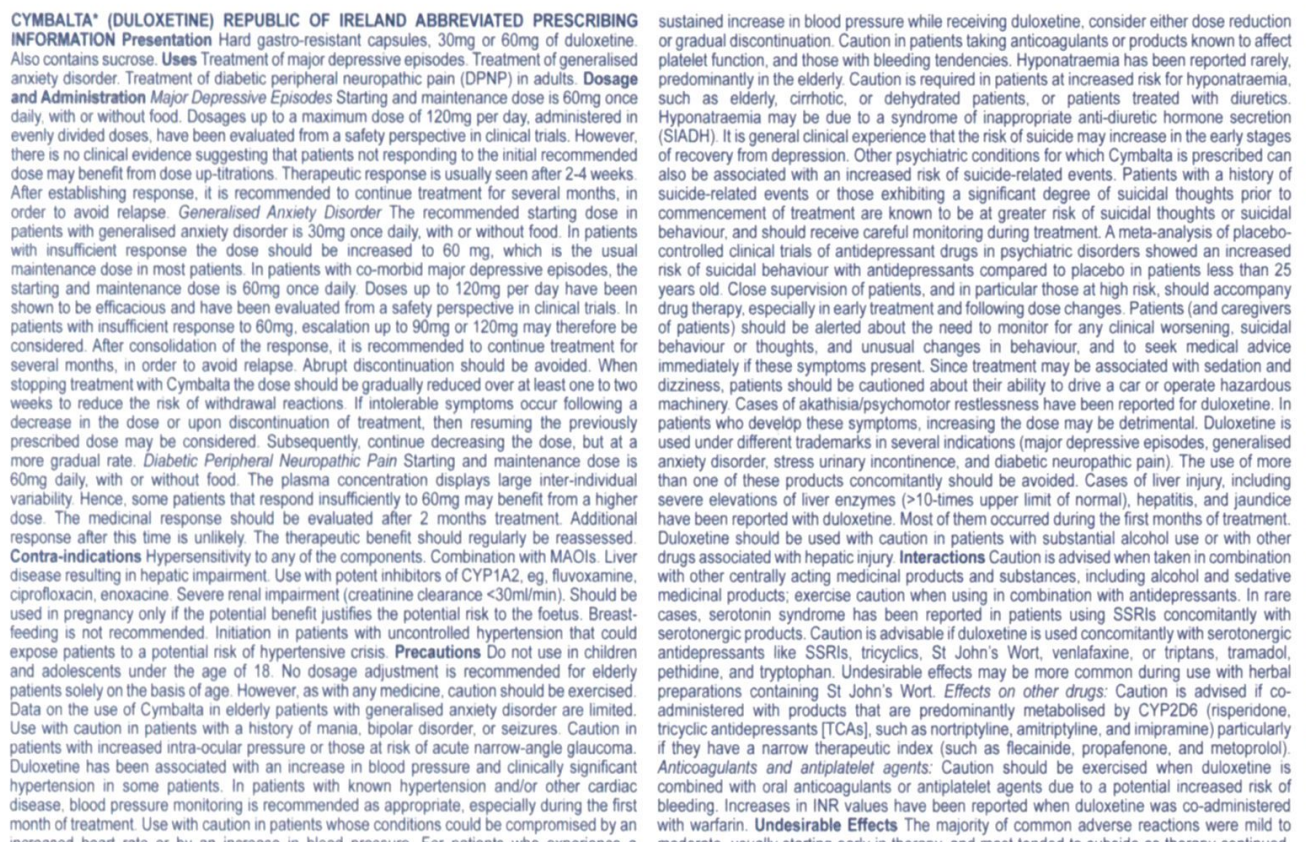

